\title{
Titration of the intertrial interval in matching-to-sample
}

\author{
G. T. HOCHSTETTER \\ West Virginia University, Morgantown, West Virginia 26505 \\ and \\ GARY L. HOLT \\ Eastern Illinois University, Charleston, Illinois 61920
}

\begin{abstract}
Six pigeons were trained in matching-to-sample using a titration procedure. Three of the pigeons began each session at a 60-sec intertrial interval. During the session, two consecutive correct responses reduced the intertrial interval by 2 sec, while a single error increased the intertrial interval by 2 sec. The 60-sec intertrial interval subjects worked toward the 0-sec interval. Both groups acquired high matching accuracy. The groups differed in the distribution of errors within a session. The 60-sec intertrial interval subjects made fewer errors in the first half of a session than in the second half. The 0 -sec intertrial interval subjects made more errors in the first half of a session than in the second half of a session. Thus, the titration procedure may have some differential effects depending upon the initial levels of the variable being titrated.
\end{abstract}

In the matching-to-sample task the subject is first presented with a sample stimulus. After responding to the sample stimulus, a set of comparison stimuli are presented. Then the subject is required to select the stimulus that corresponds to the sample. Many variables, such as schedules of reinforcement (Ferster, 1960), observing responses (Eckerman, Lanson, \& Cumming, 1968), and time-out (Ferster \& Appel, 1961), have been found to affect matching-to-sample performance. Holt and Shafer (1973) have shown that the intertrial interval also affects performance in matching-to-sample. They reported that pigeons on a 0 -sec intertrial interval failed to match beyond chance levels. For subjects on intertrial intervals longer than $0 \mathrm{sec}$, a change to the 0 -sec interval decreased matching performance.

In the present experiment a titration procedure was employed to find the optimal intertrial interval. Schrier, Stollnitz, and Green (1963) reported that a titration procedure reduced training time, and that titration was superior to a gradual shaping procedure. Wunderlich (1971) showed how titration facilitated learning in retardates. By using the titration method in delayed matching-to-sample, Scheckel (1965) and Mello (1971) showed that the range of successful delayed matching for monkeys exceeded the delays reported in the literature. A titration method should show the optimal

This paper is based upon a thesis submitted to Eastern Illinois University in partial fulfillment of the requirements for the degree of Master of Arts. Reprints may be obtained from G. T. Hochstetter, Psychology Department, West Virginia University, Morgantown, West Virginia 26505, or Gary L. Holt, Psychology Department, Eastern Illinois University, Charleston, Illinois 61920 . intertrial interval at which the subjects accurately perform matching-to-sample.

\section{METHOD}

\section{Subjects}

Six White Carneaux pigeons, approximately 5 years old, were maintained within $15 \mathrm{~g}$ of $80 \%$ ad-lib weight. The subjects were divided into two groups of three pigeons each.

\begin{abstract}
Apparatus
The pigeon test chamber was $45.72 \mathrm{~cm}$ long, $30.48 \mathrm{~cm}$ wide, and $43.18 \mathrm{~cm}$ high. On the far wall of the chamber, pecking keys were mounted behind $3.175-\mathrm{cm}$-diam circles that were $5.08 \mathrm{~cm}$ apart from edge to edge. The response keys were illuminated by three IEE light-projected display cells (Model 1346). Two 6-W 120-V houselights were mounted above the response keys at the top of the chamber. All stimuli and response consequences were controlled by relay circuitry.
\end{abstract}

\section{Procedure}

Preliminary training. After magazine training, the subjects were shaped to peck at any of the illuminated keys with short latencies regardless of hue.

Matching procedure. At the start of a trial, a red, blue, or amber hue was presented on the center key. A single peck to the center key produced a comparison hue on each of the two side keys. A peck to the key of the hue that corresponded to the sample, or center key, resulted in $3 \mathrm{sec}$ access to grain. An incorrect match, a peck to the response key illuminated by a hue other than the hue of the sample, resulted in a 3-sec time-out. The time-out was followed by a correction procedure. During the correction procedure, the same stimulus sequence was represented. Following the time-out or reinforcement interval, there was a 5-sec intertrial interval (ITI). During the ITI, all stimuli lights were dark, the houselight remained lit, and the response keys were ineffective. This procedure was continued until the subjects were matching a chance accuracy.

Titration procedure. After the subjects were matching at 
$50 \%$ accuracy, the value of the ITI was under subject control. Whenever a subject made two consecutive correct responses, the ITI was reduced $2 \mathrm{sec}$. A single incorrect response increased the ITI by $2 \mathrm{sec}$. One group of pigeons began each session with an ITI of $0 \mathrm{sec}$. The other group of birds began each session with an ITI of $60 \mathrm{sec}$. The range of possible intervals was 0 to $98 \mathrm{sec}$. A session consisted of 144 correct responses.

\section{RESULTS}

All subjects acquired a high level of matching accuracy with little variability. Figure 1 shows the matching accuracy of Subject 14 and Subject 90 . Subject 14 is representative of the 0 -sec ITI subjects. Subject 90 is representative of the $60-\mathrm{sec}$ ITI subjects. Subject 14 reached three consecutive sessions of at least $90 \%$ matching accuracy in the seventh session. Subject 90 reached this level of accuracy in 12 sessions.

Figure 2 shows the relationship between the number of errors made in the first and second halves of each of the last eight sessions. The relationship is shown as a ratio of the errors made in the first half of a session divided by the errors made in the second half. A ratio greater than one shows more errors in the first half than in the second half of the session. Figure 2 shows the error ratios of Subjects 14 and 90 . Subject 14, which is representative of the 0-sec ITI group, shows more errors in the first half than in the second half of a session. Subject 90 , representative of the 60 -sec ITI group shows more errors in the second half than in the first half of a session.

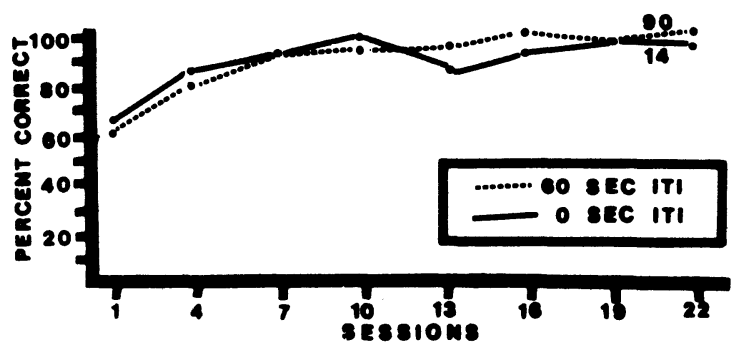

Figure 1. Acquisition of matching-to-sample performance for Subject 90 of the $60-\mathrm{sec}$ ITI group and Subject 14 of the 0-sec group.

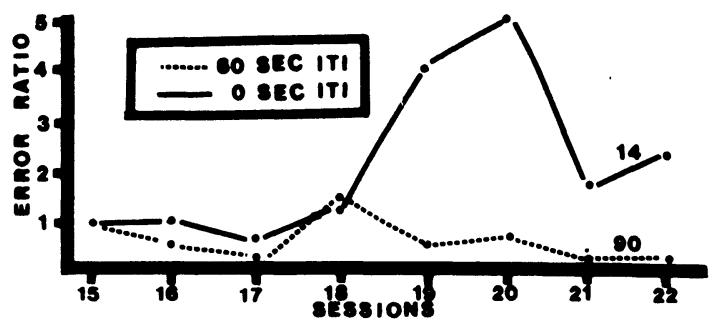

Figure 2. Relationship of errors expressed as a ratio of the errors of the first half of the session divided by the second half. Subject 14 represents the 0 -sec ITI group and Subject 90 represents the 60-sec ITI group.

\section{DISCUSSION}

A titration method was employed in this experiment so that an optimal ITI for pigeons matching-to-sample could be found. The results show that all the birds responded to produce the 0 -sec ITI. These results seem contrary to those of Holt and Shafer (1973). They reported that subjects on a 0 -sec ITI failed to match beyond chance levels. Holt and Shafer related the function of the ITI to the role of reinforcement frequency and the role of observing responses. Eckerman et al. (1968) showed that observing responses increased matching accuracy. Ferster (1960) found that a continuous reinforcement schedule resulted in lower matching accuracy than higher fixed-ratio schedules. However, in the present experiment, birds on a 0-sec ITI and a continuous reinforcement schedule showed high levels of matching accuracy. Thus, the titration method seems to be a very good procedure for training pigeons in complex discrimination. The effectiveness of titration is perhaps related to increased observing behavior, since the ITI is under subject control.

Although the results showed that both groups of birds reached high matching accuracy, there was a difference in the distribution of errors. The 60 -sec ITI group showed fewer errors in the first than in the second half of the session. The findings of Holt and Shafer (1973) are applicable here. In the first half of the session, the subject is on ITIs greater than zero. As Holt and Shafer have shown, these higher ITIs maintain high matching accuracy. However, during the second half of the session, the subject is generally on a 0 -sec ITI and performance decreases, as shown by Holt and Shafer. Although performance decreased, it was still at high levels in the present experiment. The 0-sec ITI group showed more errors in the first half than in the second half of the session. This distribution of errors may be due to the birds' habituating to the short ITI as the session progressed.

The differences in the distribution of errors show the anchoring effects of different starting positions in a titration procedure. Thus, the titration procedure may have some differential effects on performance depending upon the initial levels of the variable being titrated.

\section{REFERENCES}

Eckerman, D. A., Lanson, R. N., \& Cumming, W. W. Acquisition and maintenance of matching without a required observing response. Journal of the Experimental Analysis of Behavior, 1968, 11, 435-441.

FERSTER, C. B. Intermittent reinforcement of matching-tosample in the pigeon. Journal of the Experimental Analysis of Behavior, 1960, 3, 259-272.

Ferster, C. B., \& APPel, J. R. Punishment of $\mathrm{S} \Delta$ responding in matching-to-sample by time out from positive reinforcement. Journal of the Experimental Analysis of Behavior, 1961, 4, 45-46.

Holt, G. L., \& Shafer, J. N. Function of intertrial interval in matching-to-sample. Journal of the Experimental Analysis of Behavior, 1973, 19, 181-186.

Mello, N. K. Alcohol effects on delayed matching-to-sample performance by rhesus monkey. Physiology and Behavior, 1971, 7, 77-101.

Scheckel, C. L. Self-adjustment of the interval in delayed matching. Journal of Comparative and Physiological Psychology, 1965, 59, 415-418.

Schrier, A. M., Stollnitz, F., \& Green, K. E. Titration of spatial $S-R$ separation in discrimination by monkeys. Journal of Comparative and Physiological Psychology, 1963, 56, 848-851.

WUNDERLICH, R. A. Titration and double responding as techniques promoting proficient learning in retardates. Journal of Experimental Child Psychology, 1971, 12, 279-288.

(Received for publication March 21, 1976.) 